Revista Iberoamericana, Vol. LXIX, Núm. 205, Octubre-Diciembre 2003, 935-949

\title{
EL PERFORMANCE DEL TRAVESTÍ EN LOS TEXTOS (DES)CONOCIDOS DE ALEJO CARPENTIER
}

\author{
POR \\ James J. PANCRAZio \\ Illinois State University
}

La mujer no llevará vestido de hombre, ni el hombre vestido de mujer, porque el que hace tal cosa merece la reprobación de Yavé. (Deuteronomio 22:5)

Al abrir la novela Concierto barroco de Alejo Carpentier el protagonista criollo emprende un viaje a Europa para descubrir su lugar de origen, pero su estadía en la metrópoli lo hace consciente de su propia alteridad, y ésa toma su forma definitiva cuando el criollo (Hombre, Rico, Blanco, Católico, Eurocéntrico) asiste al Carnaval de Venecia disfrazado del emperador Moctezuma. Este performance adquiere connotaciones éticomorales más tarde cuando el criollo presta el disfraz al compositor Antonio Vivaldi para su ópera sobre la conquista de México. ${ }^{1}$ El disfraz - usurpado primero por el criollo y luego por Vivaldi-se desprende de su origen y queda asimilado a la perspectiva hegemónica en la cual el subalterno se convierte en dócil objeto en la autorrealización del metarrelato civilizador. El protagonista, ya transformado en espectador, se enfurece por la apropiación de su disfraz, lo servil de los indígenas y la cómica reconciliación entre español y mexicano al final de la ópera. Poco después se enfrenta con el compositor y lo acusa de haber alterado la historia. Sin embargo, Vivaldi responde: "no joda con la Historia en materia de teatro. Lo que cuenta aquí es la ilusión poética” (193). La ilusión del teatro es el tema de este ensayo. El disfraz y el topos barroco de la "vida como teatro" aparece en Carpentier con frecuencia (Unruh 72-3). Algunos de los ejemplos más notables del performance en la ficción de Carpentier aparecen en El reino de este mundo como las metamorfosis de Makandal, el que se viste “trajes de animales” (37), y El siglo de las luces cuando Víctor Hugues comenta: "hay tantos trajes que ya no sé cuál me corresponde” (394). Me interesa analizar la noción del disfraz como marcador del espacio liminal del performance; es un indicio corporal de lo que Gustavo Pérez Firmat ha señalado como una "translation sensibility [...] the habit of looking outward, of being on the lookout for opportunities for

\footnotetext{
${ }^{1}$ Véase el penetrante e innovador ensayo de Vicky Unruh. Para un estudio más profundo sobre el motivo del "gran teatro del mundo" en la obra de Carpentier, véase además el tercer capítulo de The Pilgrim at Home de Roberto González Echevarría. Otros estudios recientes incluyen el valioso análisis de Sally Harvey, “The Metaphor of the Theater” y el lúcido ensayo de Aníbal González sobre El arpa y la sombra.
} 
displacement, graphic and topographic” (4). Esta marcada tendencia de cruzar fronteras y apropiarse de los disfraces del otro es una constante en la obra de Carpentier. Vicky Unruh, en su ensayo sobre el espectador y el actor en la obra de Carpentier, arguye que el performance se manifiesta mediante una fluctuación entre conflictivas posiciones culturales y ontológicas. Según ella, tal como los dramaturgos más innovadores del principio del siglo veinte, Carpentier emplea la noción de performance como punto de partida en sus indagaciones teóricas sobre la ontología. Al decir de Unruh, el performance se entiende como "maneuvers before a real or imagined audience that encompass the body, the human voice or musical instruments, and space, as well as an actualizing of scripts, whether implicit or written, culturally acquired or improvised" (58). Unruh nota que la liminalidad del performance se manifiesta cuando los personajes dejan de ser espectadores y asumen papeles en el escenario o al margen de él (75). Esto corresponde precisamente a la posición del criollo de Concierto barroco quien, ante "la América de artificio" deja de sentirse espectador para asumir un papel histórico y dice: “me parecía que el cantante estuviese representando un papel que me fuera asignado, y que yo, por blando, por pendejo, hubiese sido incapaz de asumir” (198). Mi propósito, entonces, es demostrar que estas metáforas teatrales corresponden al espacio en que se realiza la identidad, el mismo espacio del travestí. Es decir que el criollo disfrazado de Moctezuma y el travestí estelar comparten el derroche espectacular, una monstruosidad que amenaza la matriz social de inteligibilidad. Este proceso queda alegorizado en Concierto barroco cuando el criollo se encara con Vivaldi y se identifica con el disfraz de Moctezuma. El criollo en esta escena expresa: "el traje de Moctezuma se hizo tremendamente mío” (198). El disfraz, de esta manera, no constituye una práctica inocente sino que marca el performance de formación cultural de una identidad que fluctúa entre varias categorías de identificación.

Generalmente el travestismo se considera como una práctica marginal en la cultura cubana, sin embargo, la metáfora del teatro sugiere que el travestí tiene derecho de reclamar un papel en la representación y la cultura cubana. Al decir de Marjorie Garber, "there can be no culture without the transvestite because the transvestite marks the entrance into the Symbolic” (354). Además, ha habido numerosos ejemplos del travestismo en la cultura literaria de la isla. Los más salientes son las narrativas que aparecen en vísperas de la independencia sobre Enrique/Enriqueta Faber: Enriqueta Faber, ensayo de novela histórica de Andrés Clemente Vázquez, Don Enriquito de Francisco Calcagno y el folleto Enriqueta Faber: médico y mujer de Pelayo Yero. Pero el travestismo no se reduce a un caso aislado sino que también se manifiesta como parte del proceso de transculturación folclórica en el appataki afrocubano del Changó y Oyá. ${ }^{2}$ Asimismo, la novela Las honradas de Miguel de Carrión presenta el caso del autor que pretende representar la voz de la mujer como escritora. Por último, el travestí aparece en casi la obra entera de Severo Sarduy: De donde son los cantantes, Escrito sobre un cuerpo, Cobra, Colibrí, y La simulación. Pero mi propósito no es demostrar el travestismo en el espacio en que es más obvio, sino en el en que se esconde y desaparece. Por tanto, me enfocaré en una serie de artículos publicados y (des)conocidos por su propio autor: Alejo Carpentier.

\footnotetext{
${ }^{2}$ Véase Efundé 55-9.
} 


\section{Los “TeXtos JACQUELINE”}

De acuerdo con la Biobibliografía de Araceli García Carranza y el Estudio biográfico crítico de Klaus Müller-Bergh, Carpentier publica una serie de artículos titulada "De la moda femenina” y “S.M. la Moda” en la revista habanera Social bajo el seudónimo de una mujer entre 1925 a 1927. “Jacqueline”, el nombre de la autora implícita, se presenta como una experta en la moda francesa. Los "Textos Jacqueline" se dedican exclusivamente a los temas de la moda femenina en Europa. Es decir que son descripciones de vestidos, trajes, carteras, zapatos, peinados, faldas, trajes de baño, negligées, joyas, boas, bufandas, sombreros; y todo tipo de material: muselina, seda, encajes, lamé, plumas, terciopelo, crepé, satín, y pieles. Cada artículo incluye fotos de modelos en los últimos vestidos de Jean Patou, Coudurier, Worth, Callot, Rodier, Jenny Lavin y Coco Chanel. Además, Jacqueline también presenta informes sobre los lugares más chic del continente: las playas de Deauville y Ostend, los cafés de París, y los resorts en Biarritz, Lido y La Riviera. En fin, estos textos presentan la fascinante noción de Carpentier haciéndose pasar por una mujer, que enseña el arte de hacerse pasar a las mujeres cubanas. Hasta cierto punto, razón tiene Severo Sarduy cuando sugiere que las mujeres imitan a los travestís (La simulación 62).

No obstante, considerar a Jacqueline como travestí por el simple hecho de ser una proyección de autoría masculina no solo es una “conclusión previsible” sino que reafirma lo que el travestismo intenta socavar: la identidad como origen. Al decir de Paul de Man, el autor en el texto es un modo de figuración (69). Severo Sarduy hace eco de esta misma idea cuando afirma que el travestismo implica "una especie de desaparición, de invisibilidad, d'effacement" (La simulación 14). A pesar de que Carpentier es el escritor que publica y reclama estos textos como parte de su obra, no es el -autor. O sea, son textos desautorizados en los dos sentidos de la palabra: son apócrifos porque Jacqueline no existe y porque la temática socava la noción del autor como origen. Por tanto, lo que pretendo hacer en este ensayo es demostrar que Jacqueline es un travestí y que este travestismo consta de un tercer modo de articulación, “a way of describing a space of possibility. Three puts in question the idea of one, self-sufficiency, self-knowledge” (Garber 11).

\section{CRISIS EN LA ALTA CUL/COS-TURA CUBANA}

Regina Root, en "Tailoring the Nation”, observa que el atavío tiene funciones tan evidentes que se consideran triviales o se olvidan. Sin embargo, en la Argentina del siglo XIX varios escritores de influencia emplean esta aparente trivialidad para importar ideales revolucionarios para modernizar el país (89). Asimismo, en la época en que aparecen los “Textos Jacqueline” Cuba está en la mitad de una crisis cultural. Al decir de Jorge Mañach, “estamos, no en un momento de agonía, sino de crisis. Crisis significa cambio” (44). Esta época se caracteriza no solo por el estancamiento político e intelectual y la penetración norteamericana sino por la radical transformación del cuerpo político. Para muchos el progreso de formación poscolonial precisa cruzar fronteras, asimilar lenguajes, técnicas y prácticas nuevas y, al volver a la isla, adaptarlas al espacio insular (461). En gran medida, la renovación poscolonial consiste en la adopción y adaptación de modelos exógenos. Esto 
implica también una renovada curiosidad por las culturas “exógenas” que ya se radican en la isla. Robin Moore en su reciente estudio sobre la cultura afrocubana se refiere a este período como la “década crítica” cuya importancia muchas veces queda rescatada por la Primera Guerra Mundial, el Machadato y la crisis del 29. Esta es la época del tango, del jazz, del renacimiento de Harlem y del primitivismo que desemboca en el movimiento afrocubano (1-5). O sea, cruzar fronteras ya es emblemático del cambio y la crisis cultural de la nueva república.

En la estela de la independencia, las mujeres cubanas también comienzan a participar en la cultura nacional en formas nunca previstas. En On Becoming Cuban, Louis A. Pérez documenta la aparición de las mujeres en la mano de obra, las universidades y los clubes deportivos (155-7). Los “Textos Jacqueline” aparecen en un momento en que las antiguas fronteras y categorías de género se alteran y la moda se presenta como uno de los medios para construir una imagen de la nueva mujer cubana. Además, en ese entonces, la importación de copias baratas de la moda europea proporciona a las clases nuevas un medio de proyectar un estado y demostrar una movilidad social. Como afirma Pérez, "under some circumstances, clothes could facilitate the invention of a usable self by which mobility might even be realized” (315).

LA VOZ DEL AMO: LA AUTORIDAD EN LA MODA

En agosto de 1925, aparece Jacqueline como la autora de la serie "De la moda femenina” y en ella describe la Exposición de Artes Decorativas en París. Ella pregunta, “¿Cuál era el motivo que ejercía sobre nosotras, las mujeres? ¿Por qué atravesábamos el flamante puente de Alejandro III, deseosas de admirar nuevas maravillas...?” (“De la moda...” 51; énfasis mío). La pregunta principal es ¿quién habla? En cuanto a la autoridad, sería tentador presumir que es un ejemplo del hombre que impone la moda a la mujer. No obstante, para postular una autoridad masculina en los “Textos Jacqueline” se tendría que construir esa masculinidad como algo afeminado. O sea, el autor representa cómo la mujer no es para imponer la autoridad del hombre que él no puede ser.

Los “Textos Jacqueline” presentan la moda en el contexto de un sistema obligatorio de heterosexualidad. Este es precisamente el sistema que el travestí busca perturbar y reconstruir como espacio teatral. En Gender Trouble, Judith Butler se refiere a este espacio como una "matrix of inteligibility" que construye la identidad como una relación entre sexo, género, práctica y deseo (24). De modo que la moda, según el travestí, consta de una serie de normas y exigencias de un espacio en que tanto participan los hombres como las mujeres. Por tanto, cuando surge la cuestión de quién produce e impone la moda en los “Textos Jacqueline”, la autora implícita cita a Jenny Lavin, una de las diseñadoras más conocidas de los años veinte, quien afirma:

Nadie impone una moda nueva [...] Una moda es impuesta por las condiciones de la existencia en el momento en que aparece. Los tan discutidos "vestiditos" [faldas] son la resultante de una necesidad de modas prácticas, del mismo modo que los sombreros chiquitos se hacen necesarios a la mujer que cada vez más anda a pié. ("S.M. La Moda”, mayo 1926, 69) 
De manera que Jacqueline sugiere que una clara noción de autoridad desaparece en la “matriz de inteligibilidad” que siempre configura el deseo como proyección masculina. ${ }^{3}$ El pronombre “nosotras” que emplea Jacqueline también indica una desaparición en que la voz del individuo se subsume y desaparece como camaleón en una multitud. Esta desaparición también está implícita en el acto de escribir. Jacques Derrida, en Margins of Philosophy, asevera que “'written communication’ must [...] remain legible despite the absolute disappearance of every determined addressee in general for it to function as writing, that is for it to be legible" (315). La escritura tiene que ser "iterable”, el término de Derrida para la repetitividad; es una serie de códigos separada e independiente del destinatario. Luego añade:

For the written to be the written, it must continue to "act" and to be legible even if what is called the author of the writing no longer answers for what he has written, for what he seems to have signed, whether he is provisionally absent, or if he is dead, or if he does not support, with his absolutely current and present intention or attention, the plenitude of his meaning, of that very thing which seems to be written "in his name". (316)

Al decir de Paul de Man, “death is a displaced name for a linguistic predicament” (81). La firma, tanto la de Jacqueline como la de Carpentier, no solo produce la ilusión de autoría sino que marca la ausencia del autor y señala el espacio de la representación misma. En su excelente ensayo sobre la monstruosidad inherente en la autorrepresentación, Roberto González Echevarría se refiere a esta condición como "the Frankenstein-monster quality of the self as a composite of parts belonging to disparate times, yet attempting to modulate one voice to constitute an 'I'” (570-1). Desde el principio, los “Textos Jacqueline” reflejan esta monstruosidad des-autorizada que borra el nombre del creador y articula un simulacro a través de la moda.

Christopher Benfey, en el libro Men Writing the Feminine, escribe, “A man looks at himself in the mirror and sees a woman's face. What are we to make of this surprise? If he hasn't turned into a woman, why does he need a mirror to know it? And if he hasn't, who is the woman?” (123). ¿Qué es lo que ve Carpentier en el espejo cuando publica textos que emplean la voz de una mujer? Ve la escritura como la escisión entre la palabra y su origen. En otras palabras, no es Carpentier que habla sino, como afirma Roland Barthes, "it is language which speaks, not the author; to write is, through a prerequisite impersonalitity [...], to reach that point where only language acts, 'performs', and not 'me'” (143).

\section{LA INTERVENCIÓN DEL PARECER}

Desde el comienzo, Jacqueline se presenta como una figura enigmática e ilegítima, sin apellido y foto. El único indicio de identidad es un nombre de abolengo desconocido.

\footnotetext{
${ }^{3}$ En "Three Essays on the Theory of Sexuality", Sigmund Freud escribe: "if we were able to give a more definite connotation to the concepts of 'masculine' and 'feminine', it would even be possible to maintain that libido is invariably and necessarily of a masculine nature, whether it occurs in men or in women and irrespectively of whether its object is a man or a woman” (287).
} 
Tal como el apellido de Carpentier, su nombre es marca de ambigüedad. ${ }^{4}$ La identidad es también problemática por lo que propone la moda: la intervención del parecer. Normalmente la identidad se considera como una esencia o producto de una teleología, pero el vestuario y el cosmético implican un kosmos, una totalidad armónica que la apariencia inscribe en el espacio. Estos son signos de una teatralización ontológica, una espectacularidad que presenta un ser hecho de partes desmontables. A la vez, la moda es el objeto de deseo y marca del desplazamiento de ese deseo al cuerpo. Tal como el monstruo y el travestí, la moda sugiere una espectacularidad que se constituye como fetiche, la carencia del objeto de deseo y la negación de esa carencia. Por tanto, cualquier dictamen modístico nace muerto y permanece como un significado congelado en el tiempo (13). Así, la moda siempre implica la simulación. Como señala Pamela L. Caughie, el mismo problema de la identidad que clasifica el simulacro como decepción también prescribe la simulación como remedio (22). Caughie añade: "[W]hile the concept of passing is understood within a binary logic of identity, the practice actually functions in terms of a double logic: it is both the problem and the solution. The passer adopts an identity that the act of passing in part constitutes" (22).

Si la identidad ya no fuera un problema, nunca habría una necesidad de simular y, al mismo tiempo, el simulador tiene que insistir en que la identidad no sea un problema para poder lograr la simulación. Por tanto, la moda presenta la identidad como un constante performance, una figuración convencional que opera bajo la simulación.

Según Jacqueline, dentro de este espacio cultural las modas femeninas siempre han fluctuado entre dos tendencias que pueden ser calificadas como la "tiranía” y la "esclavitud”. En la primera, como afirma Jacqueline, la moda se ha servido de las mujeres y dice que "la mujer ha sido una verdadera esclava. No han bastado corsets, ballenas, pomposos mirañaques de infantas, talles reducidos a su mínima expresión, peinados casi inverosímiles, para hacer más efectiva la tiranía...” (“S.M. La Moda”, marzo 1927, 90). Además, en esta dinámica cultural, ninguna mujer se ha quedado indiferente y, por ello, se han multiplicado los medios de producir las ilusiones modísticas. Jacqueline agrega:

En todos los momentos la mujer, hostigada por su inagotable deseo de gustar, de hacerse más atractiva, ha usado su atavío como una especie de lira de Orfeo - para encantar a esas bestezuelas difíciles y voluntariosas, muy débiles a veces, que se llaman los hombres. Por ello ha multiplicado los refinamientos que la rodearon; ha perfeccionado en los menores detalles el cúmulo de exquisiteces utilizadas para poner en valor la exquisitez máxima de su persona. Y en su afán de parecer cada vez más bella, más sugestiva, en su deseo de subrayar las airosas líneas de su silueta o la gracia de su gesto, ha creado ese monstruo peligrosísimo llamado: La Moda. (89; énfasis mío)

${ }^{4}$ Ver el capítulo "Literature and Exile” en Voice of the Masters de Roberto González Echevarría. En su análisis del cuento "El derecho de asilo" el crítico discute el tema del exilio y el protagonista que se exila en su propio país para 'volver' como diplomático de otro. Esta condición paradójica de ser extranjero en su propio país forma el trasfondo del análisis que la vida y obra de Carpentier en The Pilgrim at Home. 
O sea, el impulso detrás de la moda es el deseo de ser el objeto del deseo. En términos de Freud, el deseo de "hacerse más atractiva” se deriva de la "envidia del pene”, el complejo de castración que se manifiesta como una lógica de compensación. Al respecto, Freud apunta:

She slips -along the line of a symbolic equation, one might say-from the penis to a baby. Her Oedipus complex culminates in a desire, which is long retained, to receive a baby from her father as a gift -to bear him a child. One has an impression that the Oedipus complex is then gradually given up because the wish is never fulfilled. The two wishes -to posses a penis and a child-remain strongly cathected in the unconscious and help to prepare the female creature for her later sex role. (665)

De modo que la envidia del pene se desplaza constantemente en una línea que va del pene, al padre y al marido y finalmente al hijo. Tradicionalmente, esta economía simbólica se constituye mediante las posiciones exclusivas de "tener" el falo, lo que el hombre posee, y "ser” el falo, lo que la mujer es (Butler 56). Es decir, "ser” el falo es ser el significante del deseo del otro y aparecer como este significante. Judith Butler afirma, "it is to be the object, the Other of a (heterosexualized) masculine desire, but also to represent or reflect that desire" (56).

Sin embargo, el travestí marca el punto en que el complejo de Edipo cede el paso a la "lira de Orfeo". La lira es metáfora de la segunda tendencia de la moda que menciona Jacqueline: la de la esclavitud. Pero, en este caso, en lugar de ser amo, la moda sirve $a$ la mujer. Como dice, la moda se transforma en una "aliada encantadora de su vida y de sus placeres, facilitándole la existencia en vez de complicársela” (90). Añade Jacqueline, "vivimos en una época en que todas las libertades nos son permitidas. Nunca, como ahora, las modas se han doblegado ante la voluntad todapoderosa de la mujer” (90). La lira/moda es lo que anima los objetos inanimados, lo que calma y encanta la bestia e introduce el olvido que encubre la carencia. Es una intervención de un "parecer" que, al decir de Jacques Lacan, “replaces the 'to have', in order to protect it on the one side, and to mask its lack in the other” (289). Esta intervención, a medida que esconde la carencia mantiene la economía simbólica del falo y protege al sujeto contra la ansiedad de la pérdida. La moda constituye su propia compensación que permite el despliegue y que desplaza la envidia del pene. Este desplazamiento también marca la separación entre el pene como órgano y el falo como estructura (Lacan 285, Garber 356). A pesar de que el psicoanálisis tradicionalmente aduce que el hombre es el que tiene el fetiche, Garber arguye que el travestí encarna el fetiche porque señala la carencia y la carencia de la carencia. El fetiche no es solamente una estructura metonímica sino que también es metáfora de la ambigüedad [undecidability] de la castración. Es decir que la erección del travestí en la madre fálica representa una nostalgia de una totalidad (121). La moda -como el travestí- es signo de esta carencia y el encubrimiento de la misma; es marca de la ambigüedad que se constituye como el deseo de ser el objeto del deseo y la posesión de la moda como objeto del deseo. Es el teatro de un desplazamiento fálico, el de la parte desmontable. 
EL ATAVÍO EN CRISIS

En 1919 el escritor cubano Miguel de Carrión publica Las honradas, una novela protagonizada y narrada en primera persona por Victoria, mujer cubana y símbolo de la moralidad criolla/victoriana en crisis. Este travestismo literario aparece en una crisis cultural de la categoría en que se intenta establecer una coherente ideología nacionalista que serviría para canalizar y orientar el desarrollo socio-político. Según Alberto Moreiras, este tipo de ideología en Latinoamérica funciona para “contain the potentially desaggregating tendencies of the vast mestizo and indigenous classes, as well as the remaining procolonial sectors within the leading class” (204). Esta reorganización queda mejor representada en el movimiento mambisa que marca una apertura en que los negros y los mulatos comienzan a participar en el proyecto nacional. ${ }^{5}$ En este contexto, ser cubano se consituye como una negación de la categoría racial y el desplazamiento de estas tensiones a la categoría nacional. En el ambiente de la reconstrucción republicana después del 98, la transgresión de las fronteras tradicionales de raza y género ya está en boga. Asimismo, los “Textos Jacqueline” aparecen en un ambiente de desenfrenada transgresión y desplazamiento. Uno de los primeros indicios de estos cambios socio-culturales que se registran en la moda es la emergencia de las líneas sport, que marcaron la entrada de las mujeres en el espacio masculino. En julio de 1926, Jacqueline comenta:

Pocas cosas agradan tanto a la mujer como sentirse libre de trabas por algún tiempo,
vistiéndose ligeramente con aquellos encantadores vestidos de sport, de catadura
masculina, que más que ningún otro dan a las del sexo débil la justa sensación del terreno
ganado en los fueros de los eternos "fuertes" del opuesto. (68)

Pero la masculinización de la indumentaria femenina va más allá de un simple jumper, una línea algo masculina para el golf (69), se manifiesta también en el hecho de que varios diseñadores adoptan el smoking para las mujeres (67). Tradicionalmente, el traje de esmoquin es un símbolo de estatus masculino. La boga de la transgresión se culmina en 1930 con la imagen de Marlene Dietrich en la película Morocco, transvestida en esmoquin, sombrero de copas, con cigarillo en la mano y mirada irónica. Aunque no todas las líneas de esta época son obvios ejemplos del travestismo aparecen otras modas sexualmente ambiguas. Las bombachas y los jumpers que se emplean como ropa infantil unisex, marcan el mismo espacio en que aparece la flapper, la que luce el pelo corto de niño y pecho plano. Todos estos signos aluden no solo a la juventud eterna y la inmadurez, sino que son signos de lo indefinido y lo ambiguo como la elegancia de la alta sociedad.

En una crisis cultural, tal vez, lo más llamativo de Jacqueline no es la transgresión sino el esfuerzo para mantener las categorías del género. La reconstrucción de la categoría -que ya no es la misma- se constituye como un exceso, lo que Pamela Caughie ha llamado el "síndrome del caveat". Este exceso verbal no solo es un indicio de una mirada crítica de un público real o imaginario, sino que marca el límite de la simulación. Según Caughie, se define como:

${ }^{5}$ Véase, entre otros estudios importantes, Ibarra. 
an effort to protect ourselves from being accused of doing precisely what we are doing and with which we should be willing to go all the way. Indeed, the caveat, an explanation meant to prevent misinterpretation, or (more pressingly) misidentification, conspicuously characterizes most academic instances of "passing”. (30)

Estos caveats sirven para explicar las innovaciones en la moda y, al mismo tiempo, mitigar la ansiedad social ante la noción del colapso total de la categoría. Estos aparecen como otro lenguaje insertado en el discurso de Jacqueline. Por ejemplo, cuando ella se refiere a los toques masculinos en los últimos vestidos junto con el pelo corto, ella dice:

Muchas mujeres contemplaron estos vestidos con justificado temor: en efecto, si añadimos al pelo corto, a la silueta extra sencilla [pecho plano] de estos últimos tiempos, trajes de catadura masculina, ¿qué quedará de nuestra encantadora feminidad? ... Pero la moda es acomodaticia. Un insignificante detalle basta para modificar todo el carácter de un conjunto. Por otra parte se puede llevar la fantasía de los colores al vestido más austero, modificándolo totalmente. Además, la camisa que suele completar los smoking femeninos se presta a una infinidad de deliciosas combinaciones. Se la puede enriquecer con una gola en crepé de China o en encajes plissé. Una chaqueta recta, color bois de rose, llevada con una faldita de cuadritos del mismo color resultaría lo menos masculino posible. (“S.M. La Moda”, junio 1926, 67-8, énfasis mío)

La pregunta retórica, “¿qué quedará de nuestra encantadora feminidad?”, no solo incorpora el lenguaje del otro sino que marca la frontera del género y la simulación. De esta manera, Jacqueline anticipa la censura y vuelve a construir una noción de lo femenino, no como la carencia tradicional sino como una diferencia que se base en un detalle insignificante. Por tanto, el impulso de un travestí como Jacqueline es manejar los detalles y transgredir las fronteras de manera tal de no iniciar el colapso total de las categorías. De modo que lo más insignificante es, a veces, lo más significativo.

\section{ESTO NO ES UNA PIPA}

El uso del tabaco también llega a ser uno de estos detalles insignificantes en la articulación de la ambigüedad. Al principio del siglo xx fumar un habano de talle Gran Corona o Montecristo se considera una actividad masculina por antonomasia. Es signo visual de la masculinidad y evoca imágenes de virilidad, poder, estatus social e incluso narrativas de iniciación. Pero también el uso del tabaco puede considerarse como un fetiche, un objeto gratificador que compensa por la carencia. Havelock Ellis, un contemporáneo de Freud, observa que la inversión sexual en las mujeres se destacaba por un notable gusto por fumar (152-4). No es de sorprender que el uso de tabaco también aparece en los “Textos Jacqueline” como la boga de los nuevos deleites femeninos. Ella observa:

Desde que la parisiense adquirió hábito - discutido aunque indudablemente encantadorde fumar, se han multiplicado los objetos que tienen por fin halagar ese ... vicio. He visto en las vidrieras de la Rue de la Paix una encantadora teoría de boquillas, de fosforeras, 


\begin{abstract}
y sobre todo de petacas en una variedad casi abrumadora. Algunos de los más bellos y originales tenían la peculiaridad de combinar el oro amarillo, con el oro verde y el oro blanco, formando líneas curvas, estrellas, figuras caprichosas, dispuestas en la estética más moderna, y sin el menor relieve. También merece citarse aparte cierto modelito de petaca con su pequeña fosforera pendiente de una cadenita ... Y basta de tentaciones por esta vez. Después de enumerar tantos objetos menudos y exquisitos, casi siento mi conciencia intranquila. (“S.M. La Moda”, abril 1926, 67; énfasis mío)
\end{abstract}

Es interesante notar que cuando Jacqueline se refiere al afán de fumar han transcurrido más de treinta años del pronunciamiento de Ellis. En este período el uso del tabaco ha cambiado debido a la popularización del cigarillo. En contraste al habano que evoca el vigor masculino, el cigarillo evoca la elegancia y la suavidad de la alta sociedad. Por eso, no se trata de una apropiación de un fetiche masculino sino de la apropiación de una práctica ya afeminada por los hombres que buscan proyectar una imagen de elegancia. Es interesante notar además que la palabra fag en inglés denota tanto un cigarrillo como un homosexual. El cigarillo consta de una práctica tan ambigua que la sociedad establece lugares especiales en que los hombres y las mujeres pueden fumar sin entremezclarse y, más adelante, las compañías tabacaleras desarrollarán cigarrillos “femeninos”, como Virginia Slims. Es decir que afeminan una práctica ya afeminada.

\title{
LA IDENTIDAD Y EL TRAVESTISMO
}

Una de las figuras más empleadas en estos textos es la metonimia; una imagen que sustituye a otra. El travestí marca la acumulación de sustituciones y compensaciones, por tanto, la femineidad no se manifiesta como carencia sino como un exceso, un suplemento que socava la lógica del binario. La identidad se deriva de la palabra en latín, idem, que se refiere a lo mismo. Por tanto, es algo idéntico a sí mismo y diferente a los demás. Pero, el travestí invierte este binario y se representa como diferente de su identidad e idéntico a su diferencia. Cuando Jacqueline se dirige a sus lectoras usa los pronombres "vosotras" o "nosotras". Es decir, ella habla a las mujeres como mujer o como parte de la colectividad. En el primer artículo de la serie, sin embargo, Jacqueline emplea la frase, "nosotras, las mujeres" (“De la moda...” 51). Al parecer, las palabras suplementarias, "las mujeres”, sirven para enfatizar que "nosotras" se refiere a "ellas". O sea, es una primera persona plural, "nosotras”, que es también una tercera persona plural, "ellas”. La necesidad del suplemento implica que el pronombre tampoco es suficiente para producir el significado del sujeto. El suplemento marca una carencia, no solo de lo masculino, sino de todo lo femenino que no sea mujer. De manera que el exceso desprende lo femenino de la mujer y los atributos -tanto gramaticales como físicos- se convierten en partes desmontables. No obstante, se podría argüir que el suplemento se debe a la necesidad de distinguir entre las mujeres y las niñas y, por eso, el suplemento solo sirve de clasificación. No obstante, la niña, como la flapper y el travestí, ocupa el espacio de la ambigüedad. No es ni mujer ni hombre, y marca una femineidad diferente a la masculinidad y diferente entre sí. Esta in-definición también sugiere que el género es una narrativa biológica que procede de lo múltiple a lo singular. En cuanto mayor de edad, en cuanto más fijo el género. 
La edad como característica definitiva del género vuelve a aparecer en las discusiones sobre el maquillaje. A medida que la moda se ha masculinizado, el maquillaje cobra una importancia nueva. La discusión del maquillaje resulta ser una analogía muy eficaz para la técnica narrativa de la cita y la traducción de otra escritura. Es decir que la voz/cara de la narradora se subsume, mediante las citas (maquillaje textual) de otra escritora. El artículo se convierte en una breve reseña del libro Seducir de la escritora francesa Lucie Delarue Mardus. En este texto traducido, la voz narrativa afirma, "La juventud auténtica de una mujer se debe a muchos detalles de su persona, pero hay uno, muy pequeño, que se parece insignificante y dice mucho acerca de la verdadera edad de su propietaria: el borde de la nariz” (“S.M. La Moda”, febrero 1926, 64-5; énfasis mío). La autenticidad y la verdad, desde esta perspectiva, son producciones del enmascaramiento. Además, Jacqueline observa, esta “juventud auténtica” se simula mediante la adopción del modelo de la nariz de un niño. Dice la narradora, "Miradlo en un niño. Liso, intacto, sin grasa, se une a la mejilla sin relucir, sin matizarse de pequeñas venas ni llenarse de oquedades imperceptibles, ni cubrirse de minúsculos puntitos negros” (65). La cara de Jacqueline, la que no se ha visto nunca, se pierde detrás de la de Delarue Mardus que, a su vez, se pierde detrás de la nariz postiza de un niño. Esta cadena significante no sugiere que la cara del niño sea el modelo ideal de la belleza femenina, sino que la juventud se constituye mediante la falta de especificidad. Hasta el mismo referente, la palabra "niño," señala el espacio de la in-definición porque se refiere a lo general y no a lo específico. De modo que ser joven es ocupar el espacio de lo indefinido, el del travestí.

EL TRAVESTISMO NACIONAL

El travestismo en muchos casos se articula en la coyuntura de clase y género, pero en la época del jazz la imagen de Josephine Baker, o la de Marlene Dietrich, transvestida de esmoquin, sombrero de copa y cantando con voz de hombre, sugiere que esta práctica también abarca los desplazamientos de la categoría de raza a la de género (Garber 280-1). O sea, Baker travestida de hombre encubre el hecho de que es afroamericana en el feudo de la mujer blanca y mujer en el feudo del hombre. Cuba, en los años veinte, es escenario de múltiples transgresiones. No solo me refiero al ejemplo de los anuncios que aparecen en revistas cubanas como Carteles, Bohemia y Social de productos para la gente de color que sirven para blanquear la piel, alisar el pelo y reducir el tamaño de los labios. Algunos de estos productos tienen el endoso de Beny Moré, Celia Cruz y Dámaso Pérez Prado (Louis A. Pérez 302). Los músicos blancos como Paquito Rodríguez, Arquimedes Pous, Blanca Becerra y Rita Montaner se hacen pasar por negros en el teatro vernáculo de este período (Moore 45). Por tanto, cuando Jacqueline se refiere a los marcadores de clase social no se dirige a las clases pudientes sino que alude a ellas como parte del imaginario cubano. A primera vista, los “Textos Jacqueline” sirven a las damas de la clase alta. Al parecer, las lectoras implícitas son las "mujeres elegantes" y "refinadas" que quieren mantenerse al tanto de la moda de la saison en París. Pero ésta es la clase que menos necesita los consejos de una revista porque ya conoce las modas de la metrópoli. Por tanto, las lectoras implícitas de los “Textos Jacqueline” son las clases nuevas que se integran a la comunidad de la nación en la época republicana. Al decir de Louis A. Pérez, este grupo 
de "secretaries, sales clerks, telephone operators, and teachers, among others, led the transition to new styles and inevitably to new ways” (315). Aunque esta simulación no cruza la frontera del género, el hecho de que el travestí enseña la práctica de simular para que las mujeres cubanas de una clase puedan hacerse pasar, sugiere que el "parecer” forma el medio de todas las posiciones en la economía simbólica. El travestí, de este modo, no es mujer sino imitación del ideal y las que le siguen son imitaciones de la imitación.

A pesar de las visiones numánticas de la cultura cubana, se considera como un espacio abierto debido a la multiplicidad socio-étnica que forma la población. Por tanto, la noción de la nacionalidad también está sujeta a una fluctuación entre múltiples referentes sociales, étnicos y nacionales. La noción de identidad que presenta Jacqueline se ubica siempre en un espacio liminal que al producirse se traslada. Por ejemplo, cuando presenta los vestidos del otoño de 1926, ella pregunta, “¿Qué líneas nuevas aportará la próxima moda? ¿Qué colores y telas usaremos?... Toda parisiense se plantea estas preguntas actualmente” (“S.M. La Moda”, octubre 1926, 69; énfasis mío). En este comentario Jacqueline marca una transición de tiempo que es también una transición de espacio y de subjetividad. Mueve de un lado a otro de un continuum que se extiende desde La Habana a París. En la primera frase el sujeto implícito sugiere que Jacqueline es parte de un grupo que incluye a todas las mujeres que siguen la moda. No obstante, el segundo sujeto, "toda parisiense”, excluye a todas que no son de París. Tal como la escritura de Carpentier, Jacqueline tampoco emplea las comillas para indicar los cambios de perspectiva y Mikhail Bakhtin se refiere a este fenómeno como la introducción de otro lenguaje en forma encubierta porque no lleva los marcadores formales que acompañan ese lenguaje (303). Añade Bakhtin, “this is not just another's speech in the same 'language' -it is another's utterance in a language that is itself 'other' to the author as well” (303). O sea, el lenguaje de las parisienses está en el de Jacqueline y el español que emplea es también el lenguaje del otro. Jacqueline está adentro y afuera; es cubana a través de un idioma extranjero. Al decir de Marjorie Garber, "the transvestite is both a signifier and that which signifies the undecidablility of signification. It points toward itself- or, rather, toward a place where its is not" (37).

LA PEDAGOGÍA DEL TRAVESTÍ

En en libro La simulación Severo Sarduy comenta que el travestismo se manifiesta como una "pulsión letal” que “emana más bien del camuflaje, que es una desaparición, una pérdida ficticia de la individualidad que se disuelve y deja de ser reconocible” (16). Al mismo tiempo, Sarduy arguye que este impulso mimético no responde a ninguna función "práctica” derivada de la competencia entre las especies o de la selección natural. Esta ostentación muestra que "existe en el mundo vivo una ley de disfrazamiento puro, una práctica que consiste en hacerse pasar por otro...” (16). De manera que la simulación se constituye como un impulso de insertarse en el espacio. Por tanto, la función de Jacqueline es didáctica; ella enseña la técnica del make over y del rehacerse como una forma de integración. Este proceso de insertarse en el espacio queda alegorizado en el artículo de Mayo de 1927, cuando Jacqueline relata el problema de una señora “distinguidísma” que está de viaje en Francia y que comete el grave error de comprar una colección entera de 
un diseñador. El problema es que la señora no comprende que los modistas crean diseños y estilos para todo tipo de mujer, por tanto, es necesario revisar una gran variedad de modelos y comprar solamente los que "se adapten absolutamente a su género de belleza, su estatura, color de tez y silueta” (“S.M. La Moda”, mayo 1927, 91). Añade Jacqueline, "nuestras mujeres que viajan ignoran, en gran parte, el verdadero sentido que dan los costureros parisienses a la palabra 'colección' [...] Ninguna parisiense genuina adquiere sus vestidos para una saison en una sola casa de modas" (90; énfasis mío). De nuevo Jacqueline enfatiza que la moda es una manera de insertarse en el espacio y lo genuino y lo auténtico no se refieren a ningún estado esencial ni compromiso político sino al conocimiento de los códigos modísticos. La lección del travestí es ver la cultura como una expresión, un estilo sin esencia, algo desarraigado del origen y hecho de partes desmontables. Estas lecciones en ningún momento implican la dócil imitación de los modelos hegemónicos sino que sugiere que toda cultura se constituye por un proceso de asimilación, simulación y pérdida.

FinAl DEL ESPECTÁCULO

A pesar de que las cuestiones de paternidad literaria y biografía no han sido de particular interés en este ensayo, el investigador Sergio Chaple ha argüido de manera convincente que los "Textos Jacqueline" no son los únicos ejemplos de travestismo literario en la obra de Carpentier. No solo menciona los artículos de moda y el ejemplo de la narradora/protagonista de La consagración de la primavera, sino que también ha estudiado a fondo una serie de ensayos firmados por Lina Valmont, la madre del escritor. Después de comparar estos textos con los firmados por el hijo, en el mismo período concluye que los que llevan la firma de la madre en realidad son del hijo. Una de las pruebas principales que cita Chaple es el hecho de que la madre, cuya lengua materna es el ruso, no escribe el español lo suficiente bien para el periodismo (154). No deja de ser interesante que hasta este acto de travestismo también aparece como un acto compensatorio, el fetiche que encubre la carencia en la madre. A pesar de que el propósito del actual ensayo no es indagar en la biografía de Carpentier sino en los modos de representación, queda plausible sugerir que el fetichismo es una clave para leer el estilo del escritor. El fetiche marca no solo la sustitución de símbolos sino que el tropo que más se asocia con el fetiche es la hipérbole. De modo que explica sus experimentos con un estilo barroco que es signo de la ambigüedad de la carencia y la carencia de la carencia.

\section{BibliografíA}

Bakhtin, Mikhail M. The Dialogic Imagination. Caryl Emerson y Michael Holquist, trads. Austin: University of Texas Press, 1981.

Barthes, Roland. Image-Music-Text. Stephen Heath, trad. New York: Noonday Press, 1988.

The Fashion System. Matthew Ward y Richard Howard, trads. Nueva York: Hill y Wang, 1983. 
Benfey, Christopher. “The Woman in the Mirror”. Men Writing the Feminine: Literature, Theory, and the Question of Genders. Thaïs E. Morgan, ed. Albany: SUNY Press, 1994. 123-38.

Butler, Judith. Gender Trouble: Feminism and the Subversion of Identity. New York: Routledge, 1990.

Calcagno, Francisco. Don Enriquito. La Habana: Imp. “El Pilar” de M. de Armas, 1895. Carrión, Miguel de. Las honradas. La Habana: Letras Cubanas, 1981.

Carpentier, Alejo. Concierto barroco. México: Siglo XXI, 1983. La consagración de la primavera. Madrid: Siglo XXI, 1979. El reino de este mundo. Barcelona: Seix Barral, 1967. El siglo de las luces. Barcelona: Seix Barral, 1965. Jacqueline [Alejo Carpentier], “De la moda femenina.” Social (La Habana, agosto 1925): 51-3. “S.M. La Moda.” Social (La Habana, enero 1926): 69-72. “S.M. La Moda.” Social (La Habana, febrero 1926): 63-5. “S.M. La Moda.” Social (La Habana, abril 1926): 65-7 “S.M. La Moda.” Social (La Habana, mayo 1926): 67-70. “S.M. La Moda.” Social (La Habana, junio 1926): 67-70. “S.M. La Moda.” Social (La Habana, julio 1926): 67-70. "S.M. La Moda.” Social (La Habana, octubre 1926): 69-72 “S.M. La Moda.” Social (La Habana, marzo 1927): 89-91 “S.M. La Moda.” Social (La Habana, mayo 1927): 89-91.

Caughie, Pamela L. Passing and Pedagogy. Urbana: The University of Illinois Press, 1999.

Chaple, Sergio. Estudios de narrativa cubana. La Habana: Unión, 1996.

Derrida, Jacques. Margins of Philosophy. Alan Bass, trad. Chicago: The University of Chicago Press, 1982.

Efundé, Agún. Los secretos de la santería. Miami: Cubamérica, 1978.

Ellis, Havelock. “Sexual Inversion in Women”. Alienist and Neurologist 16/2 (Saint Louis, 1895): 152-4.

Freud, Sigmund.The Freud Reader. Peter Gay, ed. Nueva York y Londres: W.W. Norton, 1989.

Garber, Marjorie. Vested Interests: Cross-dressing and Cultural Anxiety. Londres y Nueva York: Routledge, 1992.

García Carranza, Araceli. Biobibliografía de Alejo Carpentier. La Habana: Letras Cubanas, 1984.

González, Aníbal. “Ética y teatrialidad: El retablo de las maravillas de Cervantes y El arpa y la sombra de Alejo Carpentier”. La Torre 7/27-8 (Río Piedras, 1993): 485-502.

González Echevarría, Roberto. The Pilgrim at Home. Austin: University of Texas Press, 1988.

“Autobiography and Representation in La Habana para un Infante difunto” World Literature Today 61/4 (Norman, 1987): 568-74.

The Voice of the Masters: Writing and Authority in Modern Latin American Literature. Austin: University of Texas Press, 1985. 
Harvey, Sally. "The Metaphor of the Theatre”. Carpentier's Proustian Fiction: The Influence of Marcel Proust on Alejo Carpentier. Londres: Támesis, 1994. 109-39.

Ibarra, Jorge. Ideología mambisa. La Habana: Instituto del Libro, 1967.

Lacan, Jacques. Écrits: A Selection. Alan Sheridan, trad. Nueva York: Norton, 1977.

Man, Paul de. The Rhetoric of Romanticism. New York: Columbia University Press, 1984.

Mañach, Jorge. La crisis de la alta cultura cubana e Indagación del choteo. Miami: Universal, 1991.

Moore, Robin D. Nationalizing Blackness. Pittsburgh: University of Pittsburgh Press, 1997.

Moreiras, Alberto. "Pastiche Identity, and Allegory of Allegory”. Latin American Identity and Constructions of Difference. Amaryll Chanady, ed. Minneapolis: University of Minnesota Press, 1994. 204-38.

Müller-Bergh, Klaus. Alejo Carpentier: estudio biográfico-crítico. Madrid: Anaya, 1972.

Pérez Firmat, Gustavo. The Cuban Condition. Cambridge: Cambridge University Press, 1989.

Pérez, Jr., Louis A. On Becoming Cuban: Identity, Nationality and Culture. Chapel Hill y Londres: The University of North Carolina Press, 1999.

Rojas, Rafael. Isla sin fin. Miami: Universal, 1998.

Root, Regina. “Tailoring the Nation: Fashion Writing in Nineteenth-Century Argentina”. Fashion Theory 4/1 (Oxford, 2000): 89-121.

Sarduy, Severo. La simulación. Caracas: Monte Ávila, 1982. De donde son los cantantes. Barcelona: Seix Barral, 1980. Colibrí. Barcelona: Argos Vergara, 1984.

Escrito sobre un cuerpo: ensayos de crítica. Buenos Aires: Sudamericana, 1969. Cobra. New York: Dutton, 1975.

Unruh, Vicky. “The Performing Spectator in Alejo Carpentier's Fictional World”. Hispanic Review 66 (Philadelphia, 1998): 57-77.

Vázquez, Andrés Clemente. Enriqueta Faber, ensayo de novela histórica. La Habana, Impr. y papelería “La Universal” de Ruiz y hermano, 1894. 